\title{
Antitumor effects of recombinant human adenovirus-p53 against human cutaneous squamous cell carcinoma in mice
}

\author{
YUANCHAO LI ${ }^{1}$, WEI HE ${ }^{1}$, RUPENG WANG ${ }^{1}$, LIBIN YANG ${ }^{2}$, CHUNLI ZHOU $^{1}$ and BIN ZHANG ${ }^{1}$ \\ ${ }^{1}$ Department of Dermatology, Xinqiao Hospital, Third Military Medical University, Chongqing 400037; \\ ${ }^{2}$ Department of Endocrinology, Friendship Hospital of Urumqi City, Urumqi, Xinjiang Autonomous Region 830049, P.R. China
}

Received August 4, 2015; Accepted September 15, 2016

DOI: $10.3892 /$ etm.2016.3901

\begin{abstract}
The present study was conducted to identify the anti-tumor effects of $\mathrm{rAd} / \mathrm{p} 53$, which is a recombinant human serotype 5 adenovirus, in cutaneous squamous cell carcinoma (cSCC). Mouse models of human cSCC were constructed by injecting human cutaneous squamous cell carcinoma cells into both flanks of nude mice. Subsequently, the 75 nude mice with cSCC xenograft tumors were randomly divided into recombinant human serotype 5 adenovirus (rAd)/p53, $\mathrm{rAd} / \mathrm{p} 53+5$-fluorouracil $(5-\mathrm{Fu})$ and 5 -Fu groups. One side of the tumors was administered the therapeutic agents as the therapeutic group, whereas the remaining side was treated with medical saline as the control. At 24, 48, 72, 120 and $168 \mathrm{~h}$ post-intratumoral injection, alterations in tumor volume, tumor necrosis and the expression of several tumor-associated genes, including Smad4, Brcal and matrix metalloproteinase (MMP-2), were analyzed. Compared with its control group, the rAd/P53 group exhibited a significantly increased tumor necrosis ratio. In addition, Smad4 and Brcal expression levels increased significantly at various time points $(\mathrm{P}<0.05)$, and MMP-2 expression decreased significantly $(\mathrm{P}<0.05)$. In the $\mathrm{rAd} / \mathrm{p} 53+5-\mathrm{Fu}$ group, the tumor necrosis ratio, and Smad4 and Brcal expression levels also significantly increased at various time points $(\mathrm{P}<0.05)$. MMP-2 gene transcription gradually decreased, high expression of Smad4 was prolonged, and high expression of Brcal was observed in the early period following treatment compared with the rAd/P53 group. In addition, p53 expression exhibited a positive correlation with the tumor necrosis ratio and Smad4 expression, and showed a negative correlation with MMP-2 gene transcription $(\mathrm{P}<0.05)$. These findings indicate that $\mathrm{rAd} / \mathrm{p} 53$ has a potent anti-tumor effect in
\end{abstract}

Correspondence to: Dr Wei He or Dr Rupeng Wang, Department of Dermatology, Xinqiao Hospital, Third Military Medical University, 83 Xinqiao Street, Shapingba, Chongqing 400037, P.R. China

E-mail: weihewhh@163.com

E-mail:wrp71@163.com

Key words: human cutaneous squamous cell carcinoma, xenograft model, mice, recombinant human serotype 5 adenovirus/p53, 5-fluorouracil
$\mathrm{cSCC}$ via the promotion of tumor necrosis and regulating the expression of various tumor-associated genes.

\section{Introduction}

Cutaneous squamous cell carcinoma (cSCC) is the second most frequent malignancy, particularly in fair-skinned individuals, second only to cutaneous basal cell carcinoma (1). Surgical excision remains the gold standard therapy for the majority of patients with cSCC since it allows adequate treatment for tumors via histological examination of the margins of the excised tissues (2). However, in many patients, these lesions may metastasize to new body sites, leading to poor prognosis (3). For metastatic cSCC, curative treatment is no longer available, and the effectiveness of chemotherapy or the treatment with reported biologic-response modifiers remains unknown (4); therefore it is crucial that novel treatment strategies against cSCC are explored.

Cumulative exposure to ultraviolet $\mathrm{B}$ radiation from sunlight is a major cause of cSCC (5). Ultraviolet radiation is able to generate specific mutations in DNA via the formation of thymidine dimers in the p53 tumor-suppressor gene. If these mutations are not successfully repaired, keratinocytes with dysfunctional p53 do not undergo apoptosis and instead undergo clonal expansion, leading to the formation of cSCC (6). Hence, the reconstitution of a wild-type p53 (wt-p53) gene is a promising anticancer therapy against cSCC. Gendicine, a recombinant human serotype 5 adenovirus $(\mathrm{rAd} / \mathrm{p} 53)$ in which the E1 region has been replaced by a human wt-p53 expression cassette, is the first commercial gene therapy product against multiple cancer (7). The therapeutic p53 gene in Gendicine can be delivered into the cytoplasm and the cell nucleus of the tumor target cells via an adenoviral particle infecting the tumor cells. Subsequently, the wt-p53 gene undergoes transcription and translation in tumor target cells (8). The expressed p53 genes exhibit their antitumor effects by promoting the apoptosis of tumor target cells, inhibiting the transcription of survival signals in tumor cells and activating the immune response in host cells (8). Gendicine was first reported as a treatment for head and neck cancers and was later discovered to have antitumor effects against several other malignancies (9-12). However, few studies have been performed to explore the antitumor effects of Gendicine on cSCC. 
Smad4, which is a potent tumor suppressor in various malignant neoplasms, has been reported to exhibit two anti-tumor effects in pancreatic cancer vs. head-neck cancer (13). Furthermore, downregulation of Smad4 has been demonstrated in a human cSCC cell line (A431) (14). Abnormal expression of Brca1, which is a breast cancer susceptibility gene that encodes a nuclear phosphoprotein, has been shown to be associated with the treatment failure of advanced squamous cervical cancer $(15,16)$. Matrix metalloproteinase 2 (MMP-2), a zinc-dependent endopeptidase, has a prominent role in the invasive ability of tumor cells, and it has previously been reported that MMP-2 levels may be reduced by the wt-p53 gene in p53-mutated human melanoma cells (17).

Therefore, the present study was conducted to identify the antitumor effects of Gendicine (rAd/p53) on cSCC in a mouse model via the following: i) Calculation of tumor volume; ii) assessment of tumor necrosis; iii) detection of the expression of antitumor genes, including Smad 4 and Brcal, and the pro-oncogenes of MMP-2; iv) analysis of the correlation between the expression of p53 and the above findings. In addition, the anti-tumor effects of $\mathrm{rAd} / \mathrm{p} 53$ were compared with that of 5-fluorouracil (5-Fu) and the combined therapy of $\mathrm{rAd} / \mathrm{p} 53$ with 5-Fu.

\section{Materials and methods}

Cell lines. A431 human cutaneous squamous cell carcinoma cell line was purchased from the Cell Bank of the Chinese Academy of Science (Wuhan, China). Cells were maintained in Dulbecco's modified Eagle medium (DMEM)/F-12 supplemented with $3 \%$ fetal bovine serum, $80 \mathrm{U} / \mathrm{ml}$ penicillin and $80 \mathrm{mg} / \mathrm{ml}$ streptomycin (all Gibco; Thermo Fisher Scientific, Inc., Waltham, MA, USA). Cells were cultured in a humidified incubator at $37^{\circ} \mathrm{C}$ with $5 \% \mathrm{CO}_{2}$ for 3-4 days until the cells completely covered the bottom of the flask. Subsequently, cells were enzymatically detached via treatment with $0.25 \%$ trypsin-EDTA for $5 \mathrm{~min}$, and viable cell counting was performed with trypan blue exclusion. Finally, cells were resuspended in Dulbecco's phosphate-buffered saline at $1 \times 10^{7}$ cells $/ \mathrm{ml}$ for subcutaneous inoculation.

Animals. A total of $75 \mathrm{BALB} / \mathrm{c}$ female nude mice, 6-weeks-old and weighing 19-25 g, were obtained from the animal center of Daping Hospital, Research Institute of Surgery, Third Military Medical University (Chongqing, China) and bred under pathogen-free conditions. Animals were housed under a 12-h light/dark cycle at $22-23^{\circ} \mathrm{C}$ with free access to food and water. The present animal study was approved by the Animal Use and Care Committee of Xinqiao Hospital (Chongqing, China). All animal experiments were performed in accordance with institutional guidelines. All efforts were made to minimize the animal suffering and to limit the number of mice used.

Animal tumor model and treatment groups. Mice $(\mathrm{n}=75)$ were subcutaneously injected with $0.5 \times 10^{7} \mathrm{~A} 431$ cells in both flanks to generate xenograft models. Ten days after injection, mice were randomized into three equal groups: rAd/p53 (Gendicine; Sibiono GeneTech Co., Ltd., Shenzhen, China) group $(n=25)$, 5 -Fu group $(n=25)$ and $\mathrm{rAd} / \mathrm{p} 53+5$-Fu group $(\mathrm{n}=25)$. Tumors on one side were intratumorally injected with the respective therapeutic agents (Sigma-Aldrich; Merck KGaA, Darmstadt, Germany). Injection frequency was once a week for $\mathrm{rAd} / \mathrm{P} 53$, and once every three days for 5-Fu according to the manufacturer's instructions. Tumors on the remaining side were intratumorally injected with medical saline once time and were indicated as the respective control groups. In accordance with the preparation method for gendicine, the $\mathrm{rAd} / \mathrm{P} 53$ power was dissolved in medical saline and the concentration of $\mathrm{rAd} / \mathrm{P} 53$ solution was $5 \times 10^{11}$ virus particles $/ \mathrm{ml}$. Injection dosage was set to $0.1 \mathrm{ml}$ for tumors with the largest diameters of $0.2-0.4 \mathrm{~cm}$, $0.2 \mathrm{ml}$ for $0.5-0.7 \mathrm{~cm}$ tumors, and $0.4 \mathrm{ml}$ for $0.8-1.0 \mathrm{~cm}$ tumors. Dosage of 5-Fu (250 mg:10 ml) was set to $2.5 \mathrm{mg}: 0.1 \mathrm{ml}$ for 0.2-0.4 cm tumors, $5 \mathrm{mg}: 0.2 \mathrm{ml}$ for $0.5-0.7 \mathrm{~cm}$ tumor, and $10 \mathrm{mg}: 0.4 \mathrm{ml}$ for $0.8-1.0 \mathrm{~cm}$ tumors.

Calculation of tumor volume. At each time point $(24,48,72$, 120 and $168 \mathrm{~h}$ after intratumoral injection), five mice from each group were randomly selected, and were sacrificed via an overdose of anesthetic (ketamine, $200 \mathrm{mg} / \mathrm{kg}$, i.p.; Sigma-Aldrich). The length and width of the excised tumors were measured. Tumor volume was calculated as tumor volume $=$ length $\mathrm{x}$ width ${ }^{2}$. Subsequently, tumors from both flanks of each mouse were divided into equal halves. One part was immediately frozen at $-80^{\circ} \mathrm{C}$ for western blot and reverse transcription-quantitative polymerase chain reaction (RT-qPCR) analysis, and the other was immersed in $4 \%$ formaldehyde solution, embedded in paraffin, sectioned, and stained with hematoxylin and eosin (HE) to assess the necrosis of the tumors.

Assessment of tumor necrosis. Pathologic sections stained with $\mathrm{HE}$ were evaluated by two pathologists for tumor necrosis analysis. The tumor necrosis ratio was calculated as the ratio of the necrotic area on the HE section at X100 magnification. The relative tumor necrosis ratio (rTNR) was calculated as the TNR of the therapeutic groups at each time point divided by the TNR of the corresponding control group. The mean of the evaluations by the pathologists was used for analysis.

Western blot analysis. Expression levels of adenovirus-carried wt-p53, Smad4 and Brca1 in the tumors following different treatments were detected by western blotting. Briefly, tumor tissues were first homogenized with lysis buffer on ice. Then lysates from tissues samples were isolated by centrifugation at $2,500 \mathrm{x} \mathrm{g}$ and $4^{\circ} \mathrm{C}$ for $30 \mathrm{~min}$. Total tumor protein from all tissue samples were quantified using a standard bicinchoninic acid assay (Pierce Protein Biology; Thermo Fisher Scientific, Inc., Rockford, IL, USA). After quantification, total proteins $(20 \mu \mathrm{g})$ were separated using 10\% SDS-PAGE, and transferred onto a polyvinylidene difluoride membrane. Then membranes were incubated in $5 \%$ milk in $0.1 \%$ Tris-buffered saline-Tween 20 (TBST) at room temperature for $2 \mathrm{~h}$. After washed with TBST for three times at room temperature, membranes were incubated with rabbit anti-mouse primary antibodies P53 (1:100; sc-6243), Smad4 (1:100; sc-7154), Brca-1 (1:200; sc-7869) and GAPDH (1:200; sc-367714; Santa Cruz Biotechnology, Inc., Santa Cruz, CA, USA) at $4^{\circ} \mathrm{C}$ overnight. The next day, membranes were incubated with infrared-labeled secondary antibodies (donkey anti-rabbit IRDye 800; 1:500; P/N 925-32213; LI-COR Biosciences, Lincoln, NE, USA) at room 
temperature for $1 \mathrm{~h}$ at room temperature after washed with TBST. Band intensities were scanned into the computer and analyzed with Image Pro Plus 6.0 software (Media Cybernetics, Inc., Rockville, MD, USA). The relative integral optical density (rIOD) of protein expression was calculated as the IOD of the protein in the control groups and therapeutic groups at each time point divided by the corresponding IOD of GAPDH. IOD ratio of protein expression was calculated as the rIOD of protein in the therapeutic groups at each time point divided by the rIOD of the corresponding control group.

RT-qPCR analysis. Total RNA was isolated from tumor tissues frozen at $-80^{\circ} \mathrm{C}$ using TRIzol reagent according to the manufacturer's instructions (Invitrogen; Thermo Fisher Scientific, Inc.). Containing DNA was removed by RNasefree DNase (Qiagen, Hilden, Germany). mRNA solution (4 $\mu \mathrm{l}$ ) was reverse-transcribed with $2.5 \mu \mathrm{M}$ of random 9-mer primer and RNA PCR kit (AMV; Takara Bio, Inc., Otsu, Japan) following the manufacturer's instruction. PCR amplification was performed for plain SYBR Green I detection in using Light Cycler system (Roche Diagnostic $\mathrm{GmbH}$, Mannheim, Germany) with the following primers specific for MMP-2: 5'-CTGGAATGCCATCCCTGATAA-3' (forward) and 5'-CAAACTTCACGCTCTTGAGACTTT-3' (reverse). Each reaction was conducted in a total volume of $20 \mu 1$ in glass capillary containing $1 \mu \mathrm{l}$ of cDNA, $4 \mathrm{mM} \mathrm{MgCl}, 10 \%$ LightCycler-DNA Master SYBR Green I buffer and $0.5 \mu \mathrm{M}$ of each primer. Thermal cycling condition was as follows: 45 cycles at $95^{\circ} \mathrm{C}$ for $30 \mathrm{sec}$ and $60^{\circ} \mathrm{C}$ for $30 \mathrm{sec}$. The expression of all genes was normalized against $\beta$-actin. Amplification was analyzed using the $2^{-\Delta \Delta \mathrm{Ct}}$ method (18). Each experiment both for tissue samples and cells were assayed in triplicate and the final results were determined after three independent experiments.

Statistical analysis. SPSS 19.0 statistical software (IBM SPSS, Inc., Armonk, NY, USA) was used for statistical analyses in the present study. Protein expression, mRNA duplication and tumor necrosis findings among the groups were subjected to Kruskal-Wallis testing. Comparisons between the therapeutic and control groups were performed by Wilcoxon testing. Correlations between the expression of P53 and other proteins or tumor necrosis were evaluated by calculating the Spearman's correlation coefficient. $\mathrm{P}<0.05$ was considered to indicate a statistically significant difference.

\section{Results}

Effects of rAd/p53 on tumor volume. Comparison of the effects on tumor volume between each therapeutic group and their corresponding control group was performed by Wilcoxon test and the results were shown in Fig. 1. There was no significant difference of the tumor volume between each therapeutic group and their corresponding control group at each time point $(\mathrm{P}>0.05)$. In addition, no significant difference in tumor volume was observed among the $\mathrm{rAd} / \mathrm{p} 53, \mathrm{rAd} / \mathrm{p} 53+5-\mathrm{Fu}$ and 5-Fu groups at each time point (Kruskal-Wallis test; $\mathrm{P}>0.05)$. It seemed that all drugs applied included $\mathrm{rAd} / \mathrm{p} 53$, $\mathrm{rAd} / \mathrm{p} 53+5-\mathrm{Fu}$ and $5-\mathrm{Fu}$ showed no obvious effects on tumor volume compared to their corresponding control, which was hypothesized to be caused by the relatively short observation time.

Effects of rAd/p53 on tumor necrosis. Tumor necrosis was evaluated by the ratio of the necrotic area on each HE-stained section. As presented in Fig. 2, the Wilcoxon test demonstrated significant differences in TNR between each therapeutic group and their corresponding groups at different time points.

Following injection of $\mathrm{rAd} / \mathrm{p} 53$, TNR increased significantly in the therapeutic group at 72, 120 and $168 \mathrm{~h}$ compared with that of the control group (Fig. 2A). Respective W- and P-values were $15.000,0.043 ; 15.000,0.043$ and 15.000 and 0.042 . In the therapeutic group injected with $\mathrm{rAd} / \mathrm{P} 53+5-\mathrm{Fu}$, TNR also increased significantly at 72, 120 and $168 \mathrm{~h}$ compared with that of its control group (Fig. 2B). Respective $\mathrm{W}$ - and P-values were 15.000, 0.043; 15.000, 0.043 and 15.000 and 0.043 , respectively. Following injection of $5-\mathrm{Fu}$, the TNR of the therapeutic group increased significantly at 48, 72, 120 and $168 \mathrm{~h}$ compared with that of the control group (Fig. 2C). The $\mathrm{W}$ - and P-values at 48, 72, 120 and $168 \mathrm{~h}$ were 15.000 , $0.043 ; 15.000,0.043 ; 15.000,0.043$, and 15.000 and 0.042 , respectively.

Comparison among the three therapeutic groups demonstrated that there was no significant difference in rTNR at each time point after statistical analysis by Kruskal-Wallis $(\mathrm{P}>0.05$; Fig. 2D). Our results indicated that all three treatments could increase tumor necrosis.

Effects of rAd/p53 on p53, Smad 4 and Brcal expression. The expression levels of p53, Smad 4 and Brcal following the different treatments were detected by western blot analysis. Quantitative analysis of the results are shown in Figs. 3-5, and the western blot images of p53, Smad4 and Brcal protein expression are presented in Fig. 6.

Expression levels of p53 in the rAd/p53 group increased significantly at the time point of 120 and $168 \mathrm{~h}$ when compared with that of the control group $(\mathrm{P}<0.05$; Fig. $3 \mathrm{~A})$. A significant increase in the expression of p53 was also observed in the $\mathrm{rAd} / \mathrm{p} 53+5-\mathrm{Fu}$ group at the time point of 72, 120 and $168 \mathrm{~h}$, when compared with its corresponding control group $(\mathrm{P}<0.05$; Fig. 3B). However, there was no significant difference in p53 expression levels between the 5-Fu group and its corresponding control group ( $\mathrm{P}>0.05$; Fig. 3C). p53 expression was compared among the three therapeutic groups by Kruskal-Wallis test and the results were shown in Fig. 3D. The highest expression of p53 occurred in the rAd/P53 + 5-Fu group, which was higher than that of the rAd/p53 and 5-Fu groups at 120 and $168 \mathrm{~h}$, respectively (120 h: $\chi^{2}, 4.811$; P-values, 6.818 and $0.009 ; 168$ h: $\chi^{2}, 4.811$; P-values, 0.028, 6.818 and 0.009). Moreover the expression of p53 was also significantly higher in the $\mathrm{rAd} / \mathrm{p} 53$ group, compared with the 5-Fu group at 120 and $168 \mathrm{~h}\left(\chi^{2}\right.$ 6.818 and $\mathrm{P}=0.009$ at 120 and $168 \mathrm{~h}$ ).

Expression of Smad4 increased significantly in the $\mathrm{rAd} / \mathrm{P} 53$ group at 72, 120 and $168 \mathrm{~h}$ when compared with that of the control group ( $\mathrm{P}<0.05$; Fig. 4A). A significant increase in Smad4 expression was also observed in the $\mathrm{rAd} / \mathrm{p} 53+5-\mathrm{Fu}$ group at 120 and $168 \mathrm{~h}$ when compared with its corresponding control group $(\mathrm{P}<0.05$; Fig. 4B). No significant changes in Smad4 expression were observed in the 5-Fu group compared with its control group at any of the time points $(\mathrm{P}>0.05$; 

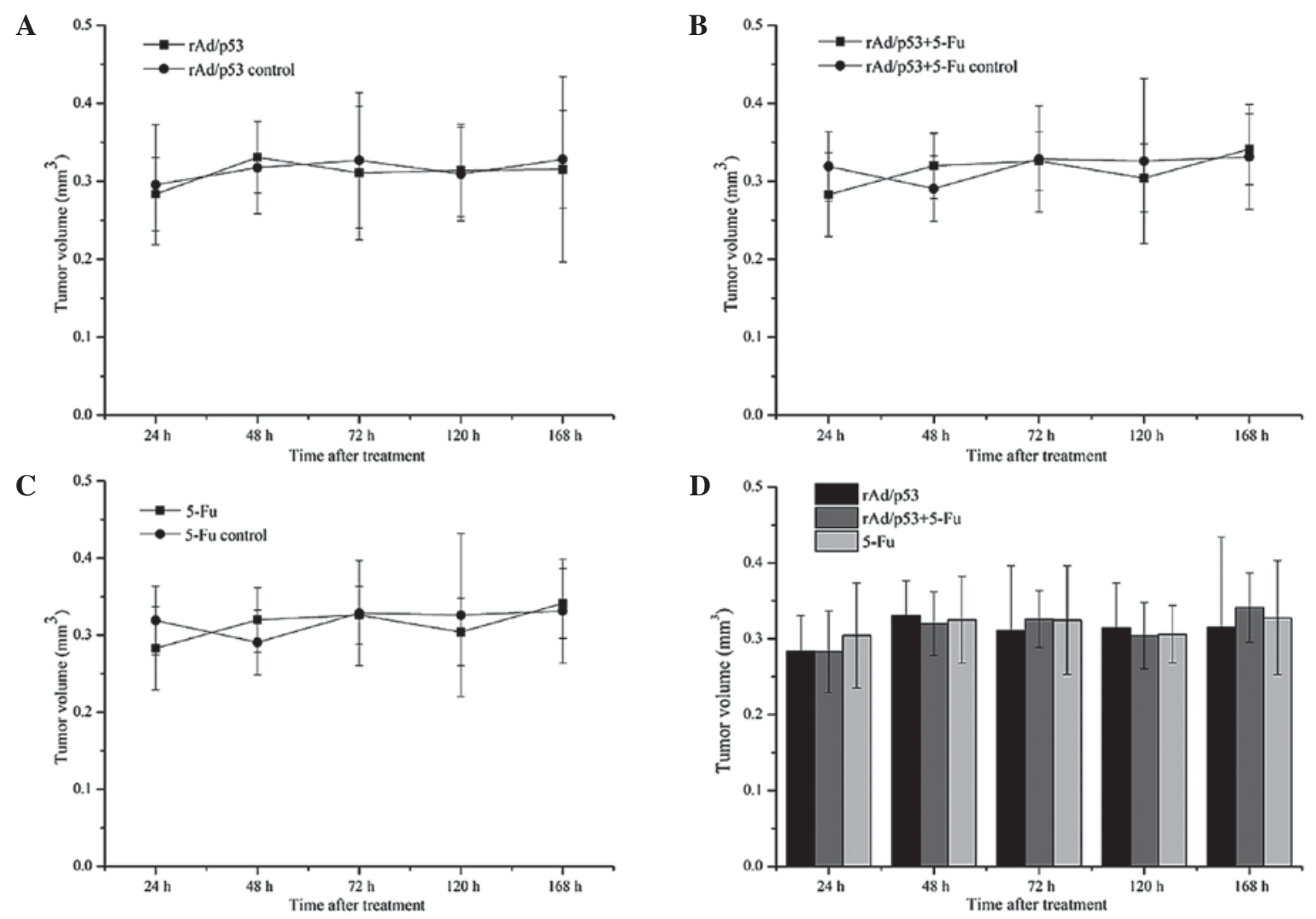

Figure 1. Effects of rAd/p53 on tumor volume in human cutaneous squamous cell carcinoma. Comparison of the (A) rAd/p53 (B) rAd/p53+5-Fu and (C) 5-Fu groups with their corresponding control groups. (D) Comparison among three therapeutic groups. Data are presented as mean \pm standard deviation.

A

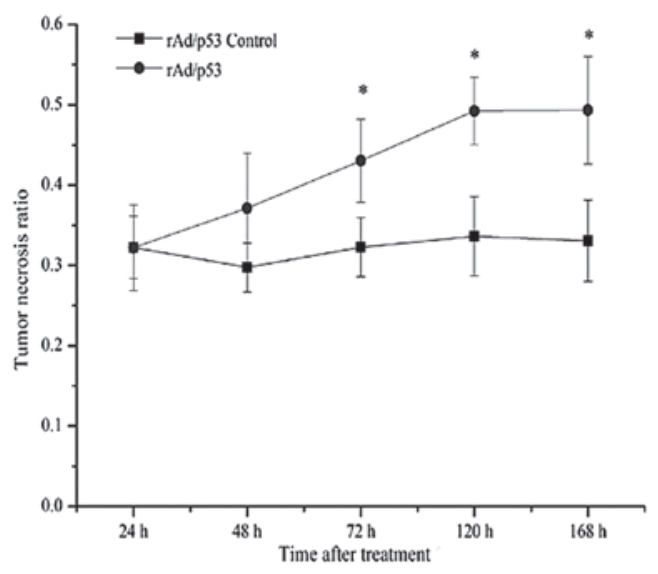

C

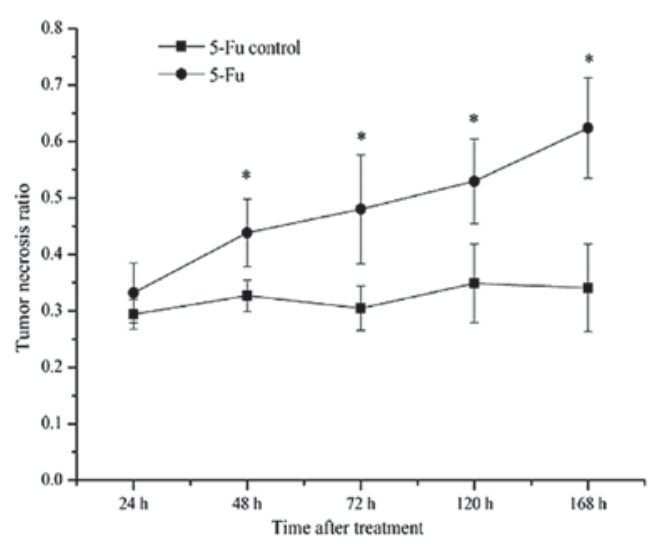

B

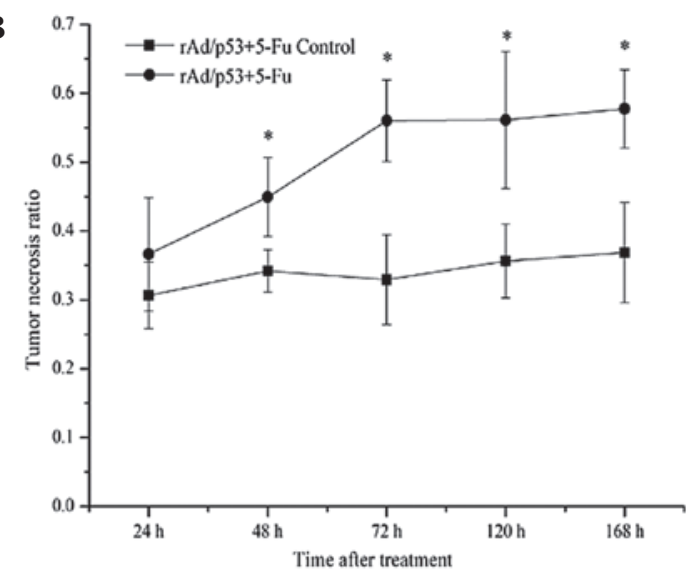

D

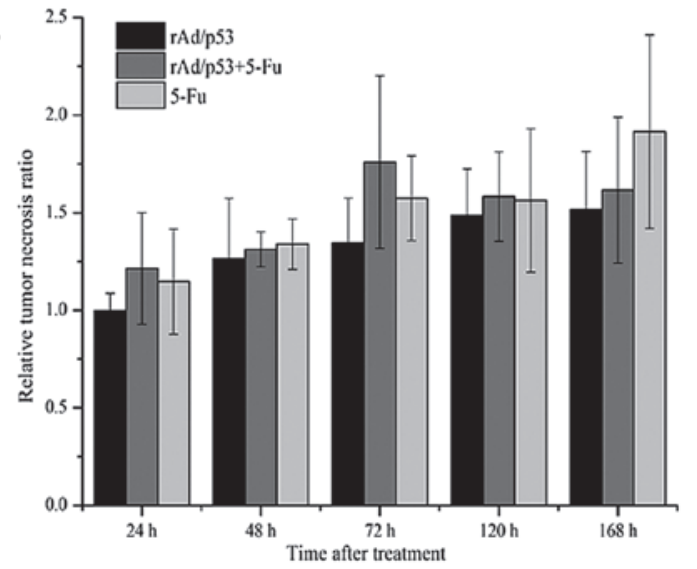

Figure 2. Effects of rAd/p53 on tumor necrosis in human cutaneous squamous cell carcinoma. Comparison of the (A) rAd/p53 (B) rAd/p53+5-Fu and (C) 5-Fu groups with their corresponding control groups. (D) Comparison among three therapeutic groups (" $\mathrm{P}<0.05$ vs. corresponding control). Data are presented as mean \pm standard deviation. 
A

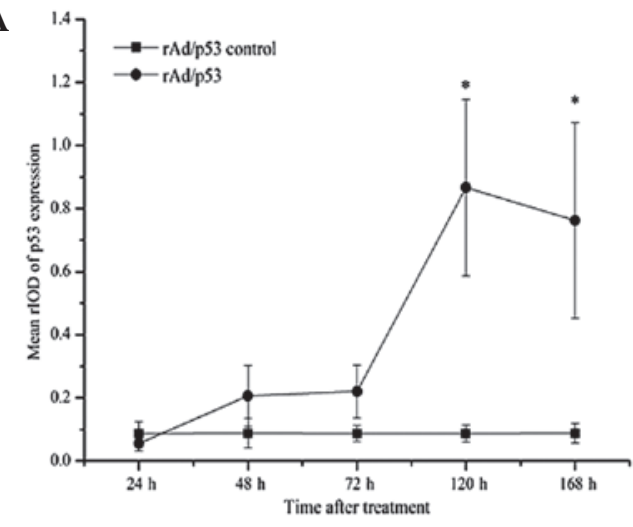

C

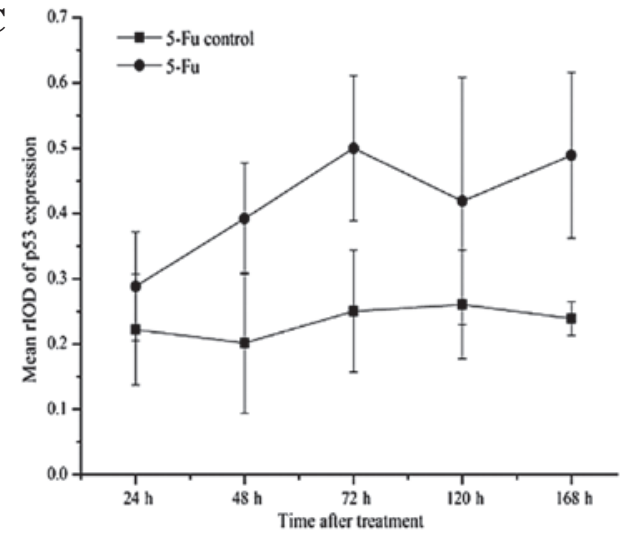

B

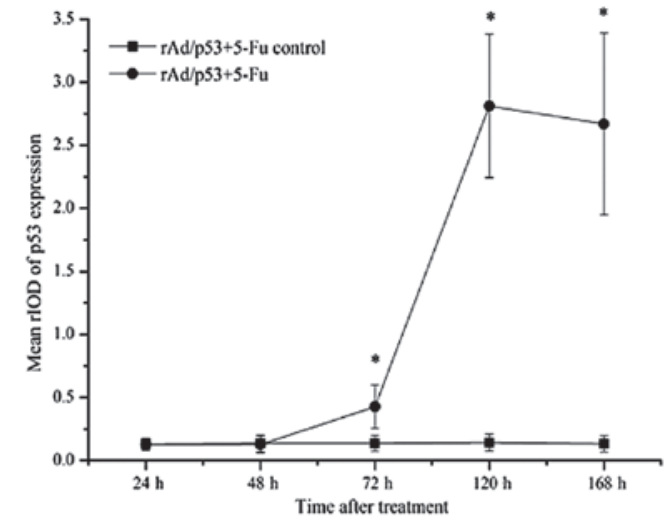

D

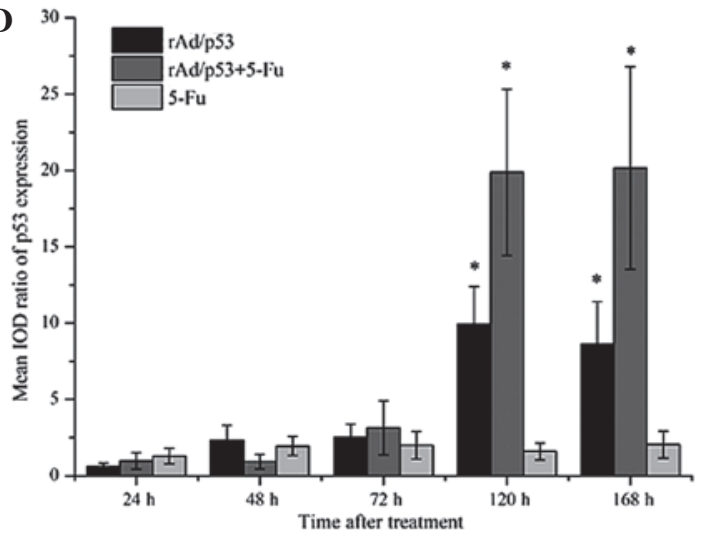

Figure 3. Expression of p53 in each therapeutic group. Comparison of the (A) rAd/p53 (B) rAd/p53+5-Fu and (C) 5-Fu groups with their corresponding control groups ( $\mathrm{P}<0.05$ vs. corresponding control). (D) Comparison among three therapeutic groups ("P $<0.05$ vs. 5 -Fu). Data are presented as mean \pm standard deviation.

A
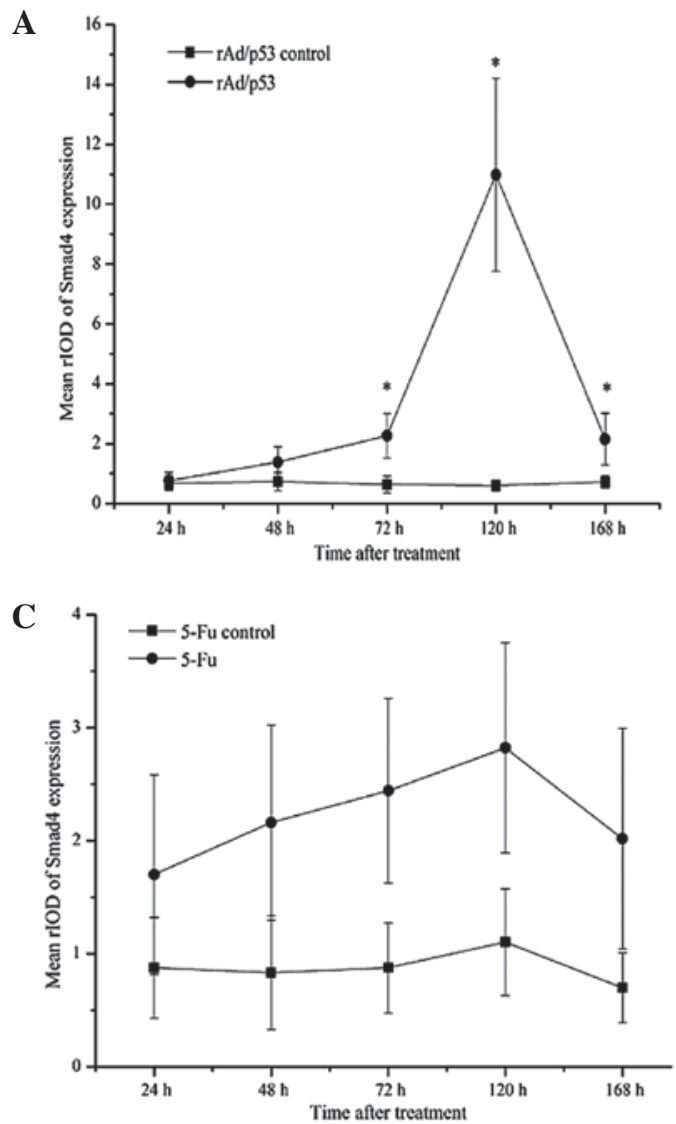
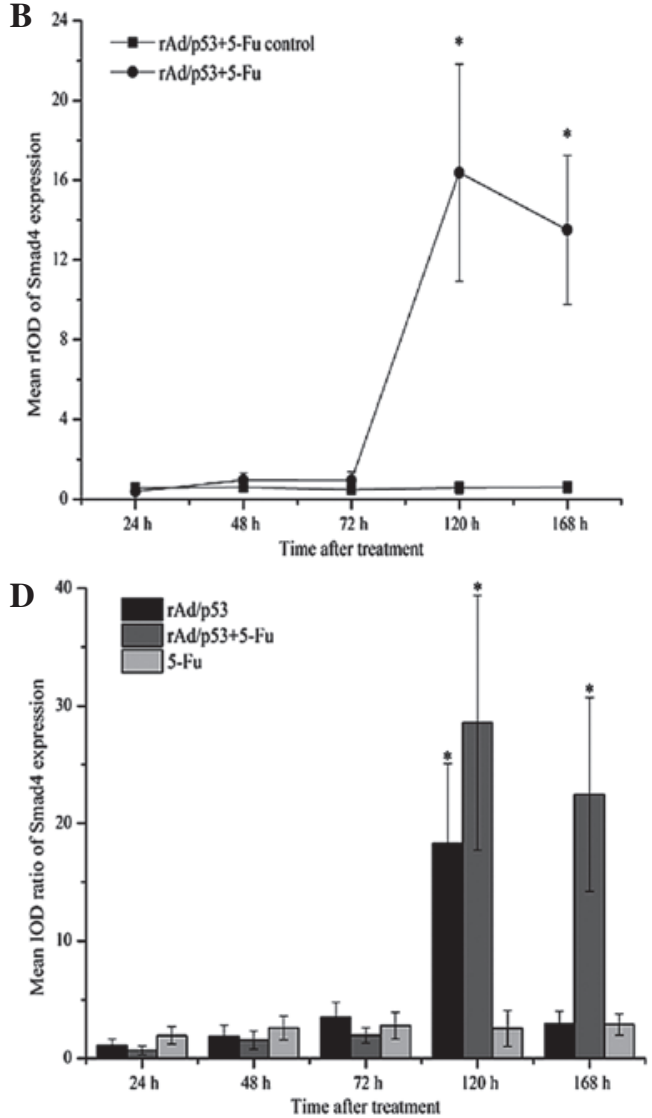

Figure 4. Effects of rAd/p53 on Smad4 expression in human cutaneous squamous cell carcinoma. Comparison of the (A) rAd/p53 (B) rAd/p53+5-Fu and (C) 5-Fu groups with their corresponding control groups (" $\mathrm{P}<0.05$ vs. corresponding control). (D) Comparison among three therapeutic groups (" $\mathrm{P}<0.05 \mathrm{vs} .5$-Fu). Data are presented as mean \pm standard deviation. 
A

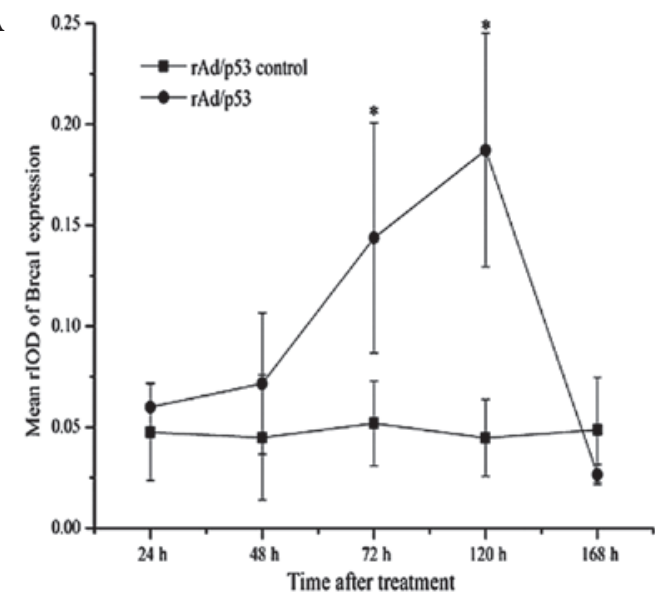

C

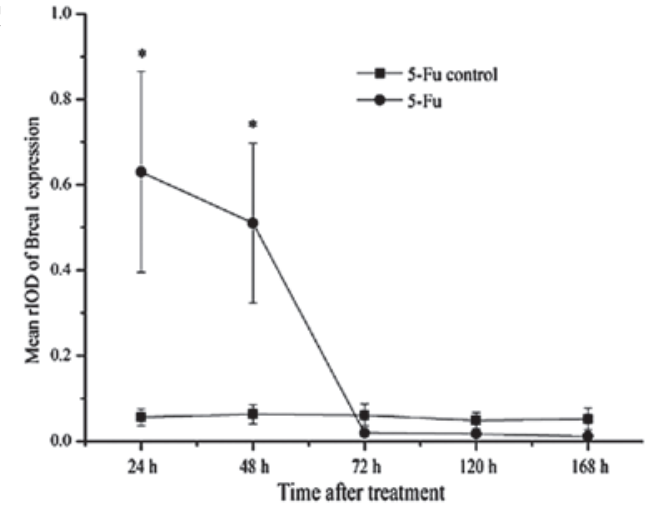

B

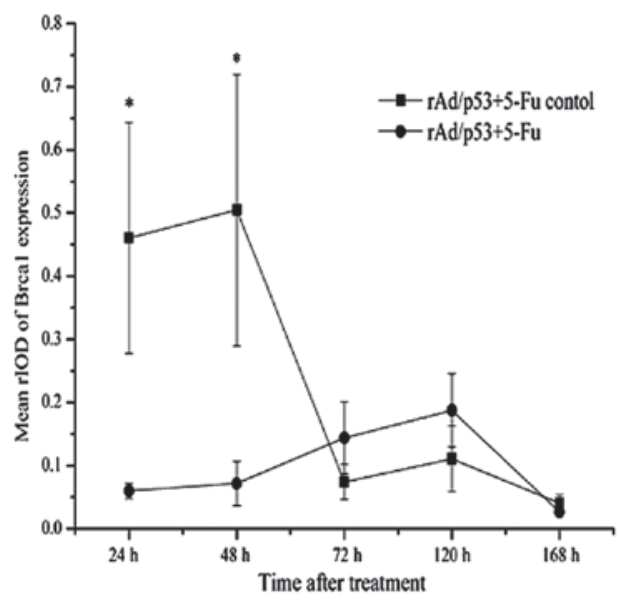

D

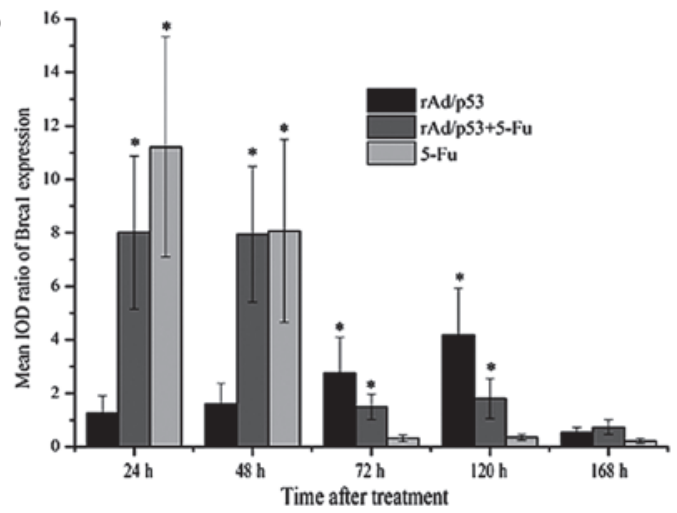

Figure 5. Effects of rAd/p53 on Brcal expression in human cutaneous squamous cell carcinoma. Comparison of the (A) rAd/p53 (B) rAd/p53+5-Fu and (C) 5-Fu groups with their corresponding control groups ( $\mathrm{P}<0.05$ vs. corresponding control). (D) Comparison among three therapeutic groups ("P<0.05 vs. 5 -Fu). Data are presented as mean \pm standard deviation.
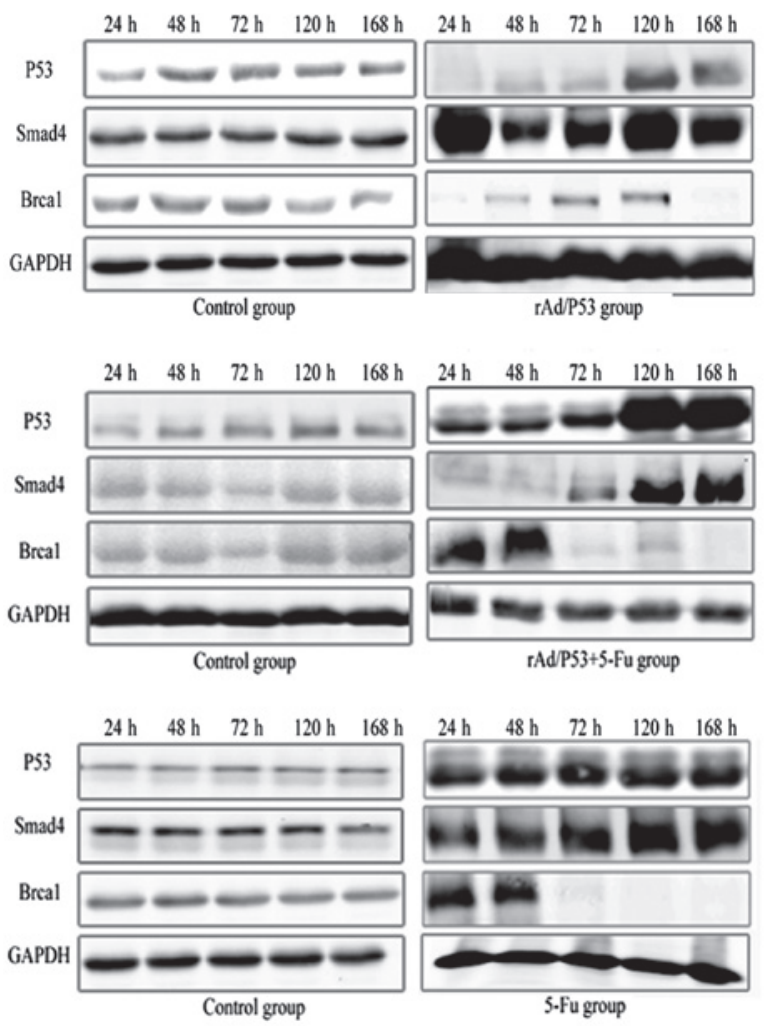

Figure 6. Expression of p53, Smad4 and Brca1 in therapeutic groups and their corresponding control groups were confirmed by western blot analysis. GADPH served as a loading control.
Fig. 4C). Kruskal-Wallis testing (Fig. 4D) demonstrated that the expression of Smad4 in the $\mathrm{rAd} / \mathrm{p} 53$ and $\mathrm{rAd} / \mathrm{p} 53+5-\mathrm{Fu}$ groups were significantly higher than that of the 5 -Fu group at $120 \mathrm{~h}$ (both $\chi^{2} 6.818$ and $\mathrm{P}=0.009$ ). At $168 \mathrm{~h}$, there was no significant difference in Smad4 expression between the $\mathrm{rAd} / \mathrm{p} 53$ and 5-Fu groups, although both of these groups exhibited expression levels lower than that of the $\mathrm{rAd} / \mathrm{p} 53+5-\mathrm{Fu}$ group $\left(\chi^{2}, 9.380\right.$ and $10.50 ; \mathrm{P}=0.009$ and 0.005 , respectively).

Changes in the expression levels of Brcal after the various treatments are presented in Fig. 5. Brcal expression in the $\mathrm{rAd} / \mathrm{p} 53$ group increased significantly at 72 and $120 \mathrm{~h}$ compared with its control group ( $\mathrm{P}<0.05$; Fig. 5A). A significant increase in Brcal expression was observed in the $\mathrm{rAd} / \mathrm{p} 53+5-\mathrm{Fu}$ and $5-\mathrm{Fu}$ groups at 24 and $48 \mathrm{~h}(\mathrm{P}<0.05)$, whereas Brcal expression decreased in both groups after $48 \mathrm{~h}$. No significant differences in Brcal expression were observed between the $\mathrm{rAd} / \mathrm{p} 53+5-\mathrm{Fu}$ or $5-\mathrm{Fu}$ groups and their corresponding groups at 72,120 and $168 \mathrm{~h}$ (Fig. 5B and C). The mean IOD ratio of each therapeutic group was analyzed by the Kruskal-Wallis test and the results are shown in Fig. 5D. Brcal expression in the $\mathrm{rAd} / \mathrm{p} 53$ group was significantly lower than that of the $\mathrm{rAd} / \mathrm{p} 53+5$-Fu and 5-Fu groups at 24 and $48 \mathrm{~h}$ (all $\chi^{2}, 6.818$ and $\mathrm{P}=0.009$ ). However, at 72 and $120 \mathrm{~h}$, Brcal expression levels in the $\mathrm{rAd} / \mathrm{p} 53$ and $\mathrm{rAd} / \mathrm{p} 53+5$-Fu groups were higher than that of the 5-Fu group $\left(\chi^{2}, 10.220\right.$ and 11.580; P-values, 0.006, 9.500 and 0.009, and 0.003, 11.180 and 0.004, respectively). These results indicated that $\mathrm{rAd} / \mathrm{p} 53$ promoted 
A

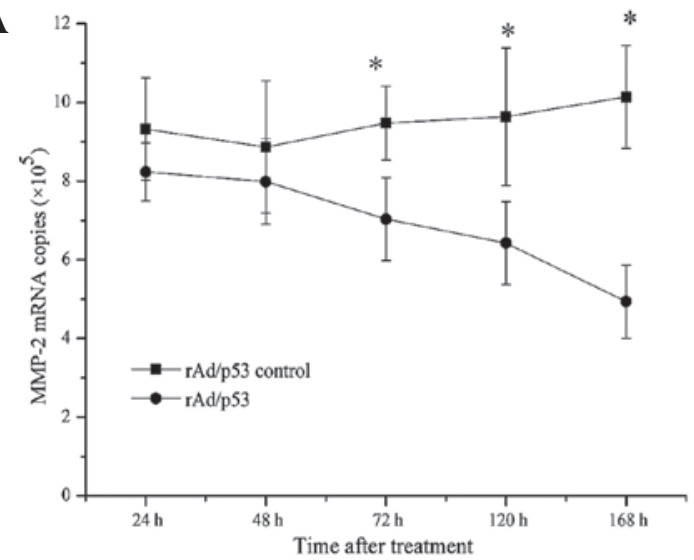

C

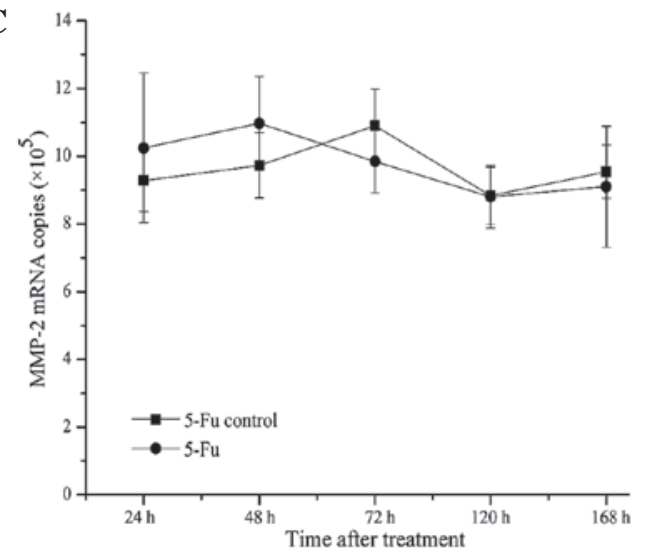

B

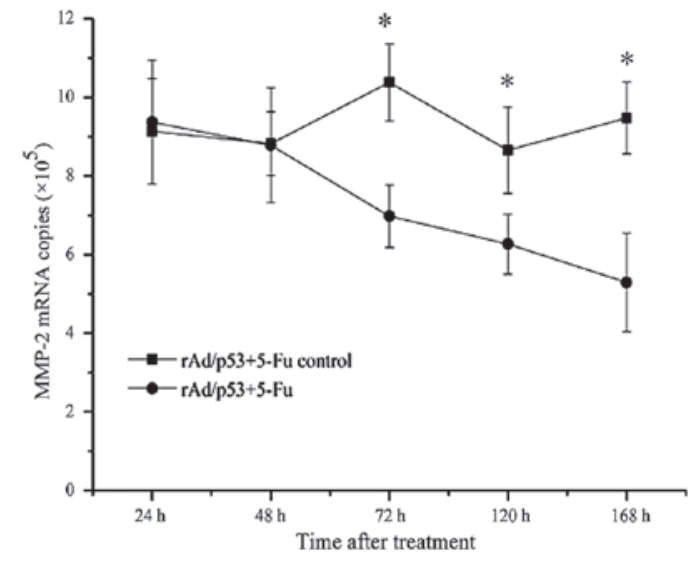

D

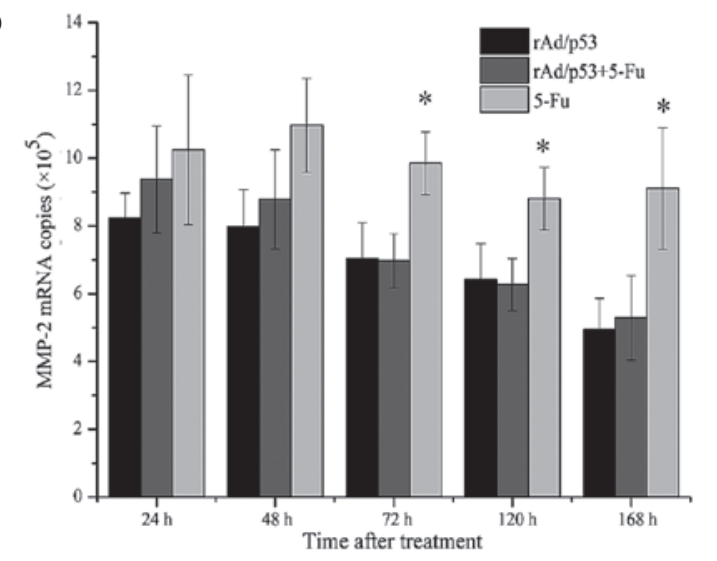

Figure 7. Effects of rAd/p53 on MMP-2 mRNA copies in human cutaneous squamous cell carcinoma, as detected by reverse transcription-quantitatve polymerase chain reaction. Comparison of the (A) rAd/p53 (B) rAd/p53+5-Fu and (C) 5-Fu groups with their corresponding control groups ("P $<0.05$ vs. corresponding control). (D) Comparison among three therapeutic groups ( $(* \mathrm{P}<0.05$ vs. 5 -Fu). Data are presented as mean \pm standard deviation.

the expression of $\mathrm{p} 53$, Smad4 and Brcal and the promoting effects on these gene expression were obviously increased of $\mathrm{rAd} / \mathrm{p} 53$ combined with 5-Fu.

Effects of rAd/p53 on MMP-2 expression. Expression levels of MMP-2 after the different treatments were detected by RT-qPCR and the results are shown in Fig. 7. Following injection of $5-\mathrm{Fu}$, there was no significant difference in MMP-2 mRNA copies between the experimental group and its corresponding control group at each time point. However, MMP-2 mRNA copies significantly decreased in the $\mathrm{rAd} / \mathrm{p} 53$ and $\mathrm{rAd} / \mathrm{p} 53+5$-Fu groups when compared with their corresponding control group from $72 \mathrm{~h}(\mathrm{P}<0.05)$. In addition, the expression levels of MMP- 2 in the $\mathrm{rAd} / \mathrm{p} 53$ and $\mathrm{rAd} / \mathrm{p} 53+5-\mathrm{Fu}$ groups were significantly lower than that of the 5-Fu group from $72 \mathrm{~h}(\mathrm{P}<0.05)$. No significant difference in MMP-2 expression was detected between the $\mathrm{rAd} / \mathrm{p} 53$ and $\mathrm{rAd} / \mathrm{p} 53+5$-Fu groups at any of the time points $(\mathrm{P}>0.05)$. Based on these results, we found that $\mathrm{rAd} / \mathrm{p} 53$ was capable of inhibiting the expression of tumor invasion and metastasis gene MMP-2.

Spearman's correlation analysis. A positive correlation was detected between the rIOD of p53 expression and the TNR (correlation coefficient, 0.574; $\mathrm{P}=0.025$ ). p53 expression also exhibited a positive correlation with the expression of Smad4 (correlation coefficient, $0.905 ; \mathrm{P}<0.001$ ). However, the rIOD of p53 expression showed no correlation with the rIOD of Brca1 expression (correlation coefficient, -0.309; $\mathrm{P}=0.263$ ). Finally, the expression of $\mathrm{p} 53$ had a negative correlation with MMP-2 mRNA expression levels (correlation coefficient, -0.598; $\mathrm{P}=0.019$ ). These results indicated that $\mathrm{p} 53$ expression is positively associated with tumor necrosis, Smad 4 expression and negatively associated with MMP-2 expression.

\section{Discussion}

Benefitting from advances of molecular genetics, targeted genes can now be successfully transferred into tumor cells. Since the p53 gene exhibits a strong suppressing effect on human malignant tumor growth, it is one of the most promising targets for gene targeted therapy (19-21). Previous studies have demonstrated that p53 gene therapy has an anticancer effect on various solid tumors in vivo and in vitro $(12,22-24)$. Recombinant human Ad/p53 was approved by the State Food and Drug Administration of China in 2003 for the treatment of head and neck squamous cell carcinoma (8). However, the anti-tumor effects of recombinant human Ad/p53 on cSCC had yet to be explored. In the present study, it was demonstrated that $\mathrm{rAd} / \mathrm{p} 53$ was able to promote tumor necrosis alone or in combination with 5-Fu. In addition, rAd/p53 upregulated the expression of potent tumor suppressors Smad4 and Brcal, and downregulated the expression of the tumor invasion and metastasis-associated gene, MMP-2. However, rAd/p53 was not demonstrated to have a significant antitumor effect on tumor volume. 
Volumetric changes in tumor growth kinetics are one of the most direct effects of therapeutic benefit of several antitumor drugs and volumetric measurements during antitumor experiments are also considered standard procedures for in vivo drug validation. In the present study, the anti-tumor effects of $\mathrm{rAd} / \mathrm{p} 53$ on tumor volume were assessed; however, there were no significant changes in tumor volume between each therapeutic group and their corresponding control groups. In addition, no significant changes in tumor volume were observed among of the three therapeutic groups. These results may be due to the short observation time of seven days. Obvious changes in tumor volume between $\mathrm{rAd} / \mathrm{p} 53$ and the corresponding control have previously been demonstrated to occur $>2$ weeks after treatment $(12,22)$.

Consistent with previous findings in animal carcinoma models $(18,23,24)$, the expression of exogenous wt-p53 exhibited a positive correlation with tumor necrosis. Similar results of the antitumor effects of $\mathrm{rAd} / \mathrm{p} 53$ on tumor necrosis were observed. $\mathrm{rAd} / \mathrm{p} 53$ was able to promote tumor necrosis alone or in combination with 5-Fu. Furthermore, the expression of p53 was demonstrated to be associated with cSCC tumor necrosis in the present study. Despite the lack of significant changes in tumor volume after treatment, $\mathrm{rAd} / \mathrm{p} 53$ showed a positively suppressive effect on cSCC through the induction of tumor necrosis.

The effects of $\mathrm{rAd} / \mathrm{p} 53$ on the expression of tumor-associated molecules in $\mathrm{CSCC}$ were also investigated in order to elucidate the antitumor mechanism of rAd/p53 in cSCC. The tumor suppressor, Smad4, which has been demonstrated to function constitutively in the transforming growth factor- $\beta$ signaling pathway, is often mutated or deleted in various malignant neoplasms, including prostate, pancreatic and colorectal cancer (25). A previous study has demonstrated that conditional knockout of Smad4 was associated with hair follicle defects and cSCC formation in mice (26). In addition, our previous study identified the downregulation of Smad4 in a human cSCC (A431) cell line (14). In the present study, wt-p53 was able to increase the expression of Smad4, and p53 expression and Smad4 expression exhibited a close positive correlation after agent administration. As described previously, wt-p53 and Smads physically interact and coordinately induce the expression of numerous tumor suppressor factors, such as sharp-1 and cyclin (27). The present findings demonstrated that exogenous p53 was able to promote the expression and function of the potent antitumor Smad4 gene, and 5-Fu was demonstrated to prolonged these effects when used in combination.

Brcal, which is a breast cancer susceptibility gene and a potent tumor suppressor, has been reported to have a role in various critical biological processes, including cell differentiation, apoptosis and DNA recombination (27). Mutation or aberrant expression of Brcal has been identified in various types of squamous cell carcinoma $(28,29)$, and Brcal is considered to be one of the biomarkers for treatment failure in advanced squamous cervical cancer (15). Due to its prominent role in squamous cell carcinoma, changes in the expression of Brcal following $\mathrm{rAd} / \mathrm{p} 53$ or control treatment were investigated in the present study. The results demonstrated that $\mathrm{rAd} / \mathrm{p} 53$ treatment alone was able to increase the expression of Brcal, and no synergistic effects on Brcal expression were detected between $\mathrm{rAd} / \mathrm{p} 53$ and 5-Fu.
MMP-2, which is a zinc-dependent proteinase, is associated with the progression, invasion and metastasis of squamous cell carcinoma, and is a potential prognostic indicator of this type of cancer $(30,31)$. In the present study, rAd/p53 treatment exhibited a strong inhibitory effect on MMP-2 expression levels and the expression of these two genes demonstrated a negative correlation. Therefore, these findings suggest that the antitumor effect of p53 may function via the downregulation of MMP-2 in cSCC.

Several limitations of the present study should be noted. Firstly, observation time of seven days to determine the antitumor effects of $\mathrm{rAd} / \mathrm{p} 53$ on tumor volume was too short to examine obvious changes between the therapeutic and control groups. Secondly, a recombinant adenovirus control was not used in the present study due to lack of resources. Thirdly, the present study was conducted in an animal model of cSCC, which did not allow for the clinical identification of the antitumor effects of exogenous p53 in cSCC; therefore, further study is required.

In conclusion, the present findings suggested that $\mathrm{rAd} / \mathrm{p} 53$ treatment may promote tumor necrosis alone or in combination with $5-\mathrm{Fu}$, and the expression of p53 was demonstrated to be associated with tumor necrosis in cSCC. In addition, $\mathrm{rAd} / \mathrm{p} 53 \mathrm{administration}$ increased the expression of various potent suppressive genes, including Smad4 and Brca1, and inhibited the expression of the tumor invasion and metastasis-associated gene, MMP-2. These results demonstrated the potent anti-tumor effects of $\mathrm{rAd} / \mathrm{p} 53$ gene therapy in cSCC. Further study is required for the clinical identification of the antitumor effects of $\mathrm{rAd} / \mathrm{p} 53$ therapy in cSCC.

\section{Acknowledgements}

The present study was supported the National Natural Science Foundation of China (grant nos. 31000455 and 30972646).

\section{References}

1. Ratushny V, Gober MD, Hick R, Ridky TW and Seykora JT: From keratinocyte to cancer: The pathogenesis and modeling of cutaneous squamous cell carcinoma. J Clin Invest 122: 464-472, 2012.

2. Motley R, Kersey P and Lawrence C; British Association of Dermatologists; British Association of Plastic Surgeons; Royal College of Radiologists, Faculty of Clinical Oncology: Multiprofessional guidelines for the management of the patient with primary cutaneous squamous cell carcinoma. Br J Dermatol 146: 18-25, 2002.

3. Kurundkar D, Srivastava RK, Chaudhary SC, Ballestas ME, Kopelovich L, Elmets CA and Athar M: Vorinostat, an HDAC inhibitor attenuates epidermoid squamous cell carcinoma growth by dampening mTOR signaling pathway in a human xenograft murine model. Toxicol Appl Pharmacol 266: 233-244, 2013.

4. Alam M and Ratner D: Cutaneous squamous-cell carcinoma. N Engl J Med 344: 975-983, 2001.

5. Thomas RF and Scotto J: Estimating increases in skin cancer morbidity due to increases in ultraviolet radiation exposure. Cancer Invest 1: 119-126, 1983.

6. Grossman D and Leffell DJ: The molecular basis of nonmelanoma skin cancer: New understanding. Arch Dermatol 133: 1263-1270, 1997.

7. Li Y, Li LJ, Wang LJ, Zhang Z, Gao N, Liang CY, Huang YD and Han B: Selective intra-arterial infusion of rAd-p53 with chemotherapy for advanced oral cancer: A randomized clinical trial. BMC Medicine 12: 16, 2014.

8. Peng Z: Current status of gendicine in china: Recombinant human ad-p53 agent for treatment of cancers. Hum Gene Ther 16: 1016-1027, 2005. 
9. Chen C, Pan J and Xu L: Recombinant adenovirus p53 agent injection combined with radiotherapy in treatment of nasopharyngeal carcinoma: A phase II clinical trial. Zhonghua Yi Xue Za Zhi 83: 2033-2035, 2003 (In Chinese).

10. Han D, Huang Z, Zhang W, Yu Z, Wang Q, Ni X, Chen X, Pan J and Wang $\mathrm{H}$ : Effectiveness of recombinant adenovirus p53 injection on laryngeal cancer: Phase I clinical trial and follow up. Zhonghua Yi Xue Za Zhi 83: 2029-2032, 2003 (In Chinese).

11. Swisher SG, Roth JA, Komaki R, Gu J, Lee JJ, Hicks M, Ro JY, Hong WK, Merritt JA, Ahrar K, et al: Induction of p53-regulated genes and tumor regression in lung cancer patients after intratumoral delivery of adenoviral p53 (INGN 201) and radiation therapy. Clin Cancer Res 9: 93-101, 2003.

12. Tu K, Zheng X, Zhou Z, Li C, Zhang J, Gao J, Yao Y and Liu Q: Recombinant human adenovirus-p53 injection induced apoptosis in hepatocellular carcinoma cell lines mediated by p53-fbxw7 pathway, which controls c-myc and cyclin E. Plos One 8: e68574, 2013.

13. Malkoski SP and Wang X-J: Two sides of the story? Smad4 loss in pancreatic cancer versus head-and-neck cancer. FEBS Lett 586: 1984-1992, 2012.

14. Zhang B, He W, Li CX, Gao T, Li Y, Yu B and Yang Y: Down-regulated expression of Smad4 in A431 cell line derived from human epidermoid squamous cell carcinoma. Zhong Qing Yi Xue 9: 017, 2008 (In Chinese).

15. Balacescu O, Balacescu L, Tudoran O, Todor N, Rus M, Buiga R, Susman S, Fetica B, Pop L, Maja L, et al: Gene expression profiling reveals activation of the FA/BRCA pathway in advanced squamous cervical cancer with intrinsic resistance and therapy failure. BMC Cancer 14: 246, 2014.

16. Larsen MJ, Thomassen M, Gerdes A-M and Kruse TA: Hereditary breast cancer: Clinical, pathological and molecular characteristics. Breast Cancer (Auckl) 8: 145155, 2014.

17. Toschi E, Rota R, Antonini A, Melillo G and Capogrossi MC: Wild-type $\mathrm{p} 53$ gene transfer inhibits invasion and reduces matrix metalloproteinase-2 levels in p53-mutated human melanoma cells. J Invest Dermatol 114: 1188-1194, 2000.

18. Livak, KJ and Schmittgen, TD: Analysis of Relative Gene Expression Data Using Real-Time Quantitative PCR and the $2^{-\Delta \Delta \text { C T }}$ Method. Methods 25: 402-408, 2001

19. Xie Q, Liang B, Zhang J, Yang Q, Gu X, Xu J and Chen M: In vivo comparison of transduction efficiency with recombinant adenovirus-mediated p53 in a human colon cancer mouse model by different delivery routes. Chin-Ger J Clin Oncol 7: 704-708, 2008 .
20. Fridman JS and Lowe SW: Control of apoptosis by p53. Oncogene 22: 9030-9040, 2003.

21. Baek JH, Agarwal ML, Tubbs RR, Vladisavljevic A, Tomita H, Bukowski RM, Milsom JW, Kim JM and Kwak JY: In vivo recombinant adenovirus-mediated 553 gene therapy in a syngeneic rat model for colorectal cancer. J Korean Med Sci 19: 834-841, 2004.

22. Xie YS, Zhang YH, Liu SP, Liu SQ, Peng CW, Wu L, Luo HS and Li Y: Synergistic gastric cancer inhibition by chemogenetherapy with recombinant human adenovirus p53 and epirubicin: An in vitro and In vivo study. Oncol Rep 24: 1613-1620, 2010.

23. Xie Q, Liang BL, Wu YH, Zhang J, Chen MW, Liu HY, Gu XF and Xu J: Synergistic anticancer effect of $\mathrm{rAd} / \mathrm{P} 53$ combined with 5-fluorouracil or iodized oil in the early therapeutic response of human colon cancer in vivo. Gene 499: 303-308, 2012.

24. Inoue H, Shiraki K, Murata K, Sugimoto K, Kawakita T, Yamaguchi Y, Saitou Y, Enokimura N, Yamamoto N, Yamanaka Y and Nakano T: Adenoviral-mediated transfer of p53 gene enhances TRAIL-induced apoptosis in human hepatocellular carcinoma cells. Int J Mol Med 14: 271-275, 2004

25. Demagny H and De Robertis EM: Point Mutations in the Tumor Suppressor Smad4/DPC4 Enhance its Phosphorylation by GSK3 and Reversibly Inactivate TGF- $\beta$ Signaling. Mol Cell Oncol 3: e1025181, 2016

26. Qiao W, Li AG, Owens P, Xu X, Wang XJ and Deng CX: Hair follicle defects and squamous cell carcinoma formation in Smad4 conditional knockout mouse skin. Oncogene 25: 207-217, 2005.

27. Elston R and Inman GJ: Crosstalk between p53 and TGF- $\beta$ Signalling. J Signal Transduct 2012: 294097, 2012.

28. Zhang X, Wei J, Zhou L, Zhou C, Shi J, Yuan Q, Yang M and Lin D: A functional BRCA1 coding sequence genetic variant contributes to risk of esophageal squamous cell carcinoma. Carcinogenesis 34: 2309-2313, 2013.

29. Seiwert TY, Zuo Z, Keck MK, Khattri A, Pedamallu CS, Stricker T, Brown C, Pugh TJ, Stojanov P, Cho J, et al: Integrative and comparative genomic analysis of HPV-positive and HPV-negative head and neck squamous cell carcinomas. Clin Cancer Res 21: 632-641, 2015.

30. de Oliveira Poswar F, de Carvalho Fraga CA, Gomes ESB, Farias LC, Souza LW, Santos SH, Gomez RS, de-Paula AM and Guimarães AL: Protein expression of MMP-2 and MT1-MMP in actinic keratosis, squamous cell carcinoma of the skin and basal cell carcinoma. Int J Surg Pathol 23: 20-25, 2014.

31. Chien MH, Lin CW, Cheng CW, Wen YC and Yang SF: Matrix metalloproteinase-2 as a target for head and neck cancer therapy. Expert Opin Ther Targets 17: 203-216, 2013. 